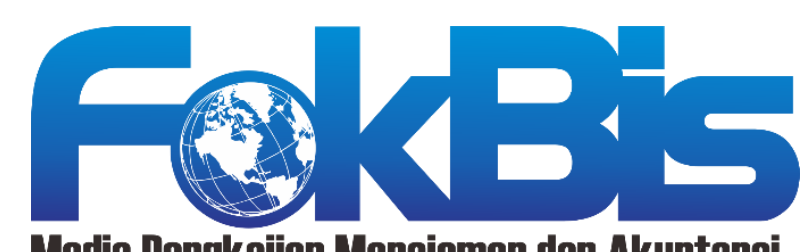

Media Pengkajian Manajemen dan Akuntansi

http://journal.stieputrabangsa.ac.id/index.php/fokbis/index

ISSN: 2623-2480/ P-ISSN: 1693-5209

\section{UPAYA MEMPERTAHANKAN BISNIS RADIO SIARAN DI TENGAH KEMAJUAN TEKNOLOGI DAN INFORMASI (Studi Pada Empat Perusahaan Radio Siaran di Kabupaten Kebumen)}

\section{Hendrawan Prasetyo}

STIE Putra Bangsa, Kebumen, Indonesia email: hendrawanprasetyo@yahoo.com

\section{Article Information}

\section{History of Article:}

Received August 21 2019

Accepted October $5^{\text {th }}, 2019$

Published December 23rd, 2019

DOI:

10.32639/fokusbisnis.v\%vi\%i.332

\begin{abstract}
The problem in this study is about how the radio broadcast business in the era of technological advancements and information, whether radio broadcasts can still maintain their existence and are still in the public interest as an effective means of entertainment and information and what radio broadcast companies do in facing business challenges in the era technological progress and information so that it can survive. The method used in this study is a qualitative research method, taking data sources using a "purposive sampling" technique with a total of four informants including the management of radio broadcast companies in four radio broadcast companies in the researched Kebumen Regency. The four radio broadcast companies in Kebumen Regency were examined, although in general they had adjusted to the advancement of technology and information in order to maintain their existence. In fact there were still a number of radio broadcast companies that had not implemented streaming broadcasts so that the range that could be received by audiences or listeners was limited and not yet global.
\end{abstract}

Keywords: Business Communication, Radio Broadcast, Technological Progress

\title{
PENDAHULUAN
}

Radio merupakan media komunikasi yang muncul pada era telekomunikasi. Kemunculan radio sebagai media komunikasi memberikan kemudahan bagi masyarakat untuk memperoleh informasi. Radio menjadi salah satu media yang menyebarkan informasi melalui audio atau suara. Namun di era kecanggihan teknologi ini tampaknya minat masyarakat untuk mendengarkan radio lebih sedikit dibandingkan tahuntahun sebelumnya karena radio hanya memberikan informasi berupa audio saja. Mengingat semakin banyaknya media massa yang berkembang baik berupa media elektronik maupun media cetak maka 
dalam hal ini media elektronik yang berupa radio yang pada mulanya merupakan teknologi yang mencari kegunaan, bukannya teknologi yang lahir sebagi respons terhadap suatu pelayanan baru, maka di era kemajuan teknologi informasi yang semakin pesat diperlukan peningkatan peran kualitas, dan fungsi radio siaran sebagai media informasi yang efektif untuk tetap mempertahankan eksistensinya. Dengan demikian radio siaran merupakan sarana penyambung informasi, dan juga merupakan sarana komunikasi yang efektif bagi masyarakat.

Menurut Effendy (2002: 6), terdapat 5 (lima) komponen yang ada dalam komunikasi yaitu : komunikator (orang yang menyampaikan pesan), pesan (pernyataan yang didukung oleh lambang), komunikan (orang yang menerima pesan), media (sarana yang mendukung pesan apabila komunikan jauh tempatnya atau banyak jumlahnya), dan efek (dampak sebagai pengaruh dari pesan). Komunikasi berlangsung apabila antara orang-orang yang terlibat dalam komunikasi terdapat kesamaan makna mengenai suatu hal yang dikomunikasikan. Sebaliknya jika ia tidak mengerti maka komunikasi tidak berlangsung dan dengan kata lain hubungan antara orang-orang itu tidak komunikatif. Selanjutnya, Cangara (2006: 115) menggambarkan kaitan antara satu unsur dengan unsur yang lain dalam komunikasi yaitu sebagai berikut (Cangara, 2006: 115):

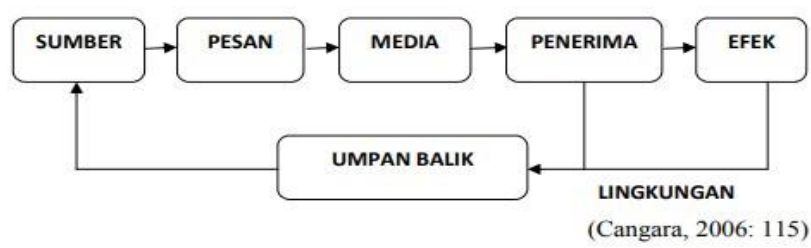

Gambar 1. Unsur-Unsur Komunikasi

\section{Identifikasi Masalah}

1. Bagaimana bisnis radio siaran di era kemajuan teknologi informasi, apakah radio siaran masih bisa mempertahankan eksistensinya dan masih diminati masyarakat sebagai sarana hiburan dan informasi yang efektif?

2. Upaya apa yang dilakukan oleh perusahaan radio siaran dalam menghadapi tantangan bisnis di era kemajuan tekologi informasi agar tetap bisa bertahan?

\section{Kerangka Pikir}

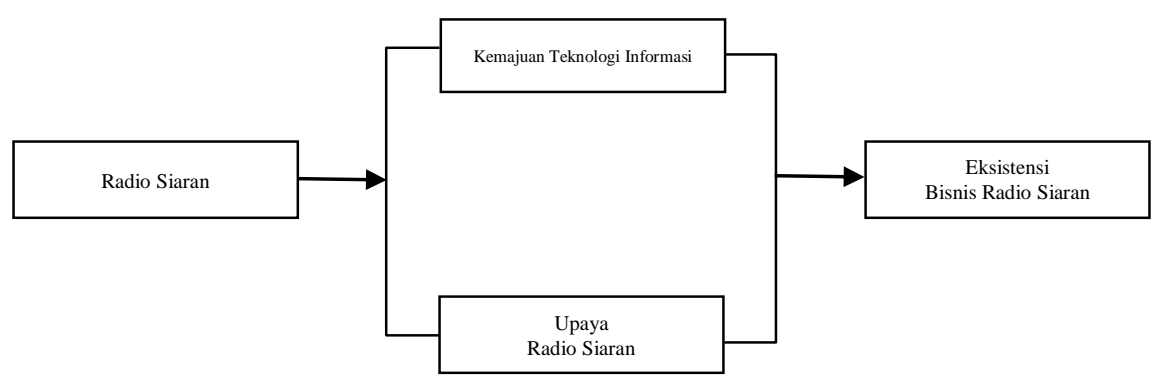

Gambar 2. Kerangka Pikir

\section{METODE}

Dalam penelitian ini, penulis menggunakan jenis penelitian deskriptif yaitu suatu penelitian yang dimaksudkan untuk menggambarkan sejumlah variabel yang berkenaan dengan masalah dan unit yang 
diteliti tanpa mempersoalkan hubungan antara variabel. Metode analisis data yang digunakan adalah kualitatif. Penelitian ini memfokuskan pada upaya yang dilakukan perusahaan radio siaran dalam mempertahankan eksistensinya di era kemajuan teknologi informasi yang semakin pesat.

Sumber Data dalam penelitian ini terdiri dari :

a. Data Primer

Data primer ini diperoleh dari hasil wawancara langsung yang berupa pernyataan-pernyataan ataupun informasi yang sesuai dengan substansi penelitian. Data primer dalam penelitian ini diperoleh melalui wawancara dengan Direktur, Pengelola, Penyiar.

b. Data Sekunder

Data sekunder berupa catatan tertulis dari instansi yang bersangkutan yang sesuai dengan substansi penelitian ini.

Dalam rangka pengumpulan data yang diperlukan maka penulis menggunakan teknik pengumpulan data sebagai berikut :

a. Observasi

Yaitu pengumpulan data yang dilakukan dengan cara mengadakan pengamatan langsung terhadap fenomena-fenomena yang terjadi sesuai dengan masalah penelitian ini.

b. Interview

Yaitu sistem pengumpulan data dengan cara mengadakan wawancara langsung dengan pihakpihak yang berwenang atau nara sumber.

c. Dokumentasi

Metode dokumentasi lebih difokuskan untuk memperoleh data yang bersifat tertulis atau dalam bentuk angka, di mana teknik ini dilakukan dengan menyalin data yang sudah ada.

Dalam penelitian ini instrumen yang digunakan adalah berupa :

a. Pedoman wawancara, merupakan daftar pertanyaaan sebagai panduan dalam mengumpulkan keterangan-keterangan dari informan.

b. Perangkat elektronik/smartphone yang dipergunakan merekam hasil wawancara dengan informan.

\section{HASIL DAN PEMBAHASAN}

Potensi siaran radio di Indonesia masih cukup menjanjikan, sekalipun tantangan teknologi informasi saat ini membuat radio juga harus bersaing dengan kemunculan berbagai media baru. Bahkan hingga saat ini, jumlah radio siaran terus berkembang cukup hebat. Demikian juga halnya dengan perkembangan radio siaran di Kabupaten Kebumen. Terdapat 9 Lembaga Penyelenggara Penyiaran di Kabupaten Kebumen . 
Tabel 1. Daftar Stasiun Radio Siaran di Kabupaten Kebumen

\begin{tabular}{|c|c|c|c|c|c|c|}
\hline No & Kanal & Frek & $\begin{array}{l}\text { Nama Lembaga } \\
\text { Penyiaran }\end{array}$ & Nama Udara & Alamat & Status Izin \\
\hline 1 & 24 & 89.9 & $\begin{array}{l}\text { PT.Radio Arta Prima } \\
\text { Perdana }\end{array}$ & Ardana FM & $\begin{array}{l}\text { Jl. Arungbinang No.9, } \\
\text { Kel. Kebumen, Kec. } \\
\text { Kebumen, Kab. Kebumen }\end{array}$ & ISR IPP \\
\hline 2 & 91 & 96.6 & $\begin{array}{l}\text { PT.Radio Suara Gaharu } \\
\text { Bima Sakti }\end{array}$ & Bima Sakti FM & $\begin{array}{l}\text { Jl. Letjen Suprapto No. } 3 \\
\text { Kel. Bumirejo Kec. } \\
\text { Kebumen, Kebumen }\end{array}$ & ISR IPP \\
\hline 3 & 142 & 101.7 & $\begin{array}{l}\text { PT. Radio Mulia Arifta } \\
\text { Swara }\end{array}$ & MAS FM & $\begin{array}{l}\text { Jl. Arungbinang No. } 9 \\
\text { Kel. Kebumen, }\end{array}$ & ISR IPP \\
\hline 4 & 158 & 103.3 & PT. Radio Leonita Insan & Prima FM & $\begin{array}{l}\text { Jl. Arungbinang No.9 } \\
\text { Kel. Kebumen, Kec. } \\
\text { Kebumen, Kab. Kebumen }\end{array}$ & ISR IPP \\
\hline 5 & 202 & 107.7 & $\begin{array}{l}\text { SMA NEGERI } 1 \\
\text { GOMBONG }\end{array}$ & INSAGO FM & $\begin{array}{l}\text { Jl. Sempor Lama No. 64, } \\
\text { Kel. Semanding, Kec. } \\
\text { Gombong, Kab. Kebumen }\end{array}$ & ISR IPP \\
\hline 6 & 204 & 107.9 & $\begin{array}{l}\text { Perkumpulan Radio } \\
\text { Komunitas DELTA FM }\end{array}$ & D FM & $\begin{array}{l}\text { Jl. Surononggo Barat No. } \\
7 \text { Kel/Ds. Kertodeso Kec. } \\
\text { Mirit Kab. Kebumen }\end{array}$ & ISR IPP \\
\hline 7 & 31 & 90.6 & LPPL Radio In FM & In FM & $\begin{array}{l}\text { Jl. Kutoarjo Nomor } 6 \\
\text { Kelurahan Panjer, } \\
\text { Kecamatan Kebumen, }\end{array}$ & ISR IPP \\
\hline 8 & 98 & 97.3 & $\begin{array}{l}\text { PT. Radio Suara } \\
\text { Arumbinang Semesta FM }\end{array}$ & Gong Radio & $\begin{array}{l}\text { Perum Jati Asri No. } 1 \text { Jl. } \\
\text { Sempor Baru KM 1, } \\
\text { Jatinegara, Sempor, Kab. } \\
\text { Kebumen }\end{array}$ & ISR IPP \\
\hline 9 & 165 & 104 & PT. Radio Purbowangi & RP FM & $\begin{array}{l}\text { Jl. Raya Purbowangi, Kel. } \\
\text { Purbowangi, Kec. } \\
\text { Buayan, Kab. Kebumen }\end{array}$ & ISR IPP \\
\hline
\end{tabular}

\section{Sumber: https://kominfo.kebumenkab.go.id/web/post/lembaga-penyiaran7}

Fokus dalam penelitian ini adalah pada upaya yang dilakukan oleh pengelola Radio Siaran dalam menghadapi kemajuan teknologi dan informasi yang semakin pesat (internet, maraknya media online/digital, dsb.) Teknologi yang dewasa ini merambah industri radio adalah radio digital, live streaming atau radio internet. Digitalisasi telah menguasai kehidupan masyarakat. Respati (2014) mengungkapkan bahwa digitalisasi merupakan transformasi masyarakat informatif yang secara memaksa dari bentuk analog ke digital. Digitalisasi tidak hanya berpengaruh pada aspek kehidupan masyarakat, melainkan juga berpengaruh pada beberapa media informasi dan telekomunikasi, salah satunya radio konvesional.

Perkembangan Teknologi Informasi dan Komunikasi mau tidak mau memaksa industri penyiaran untuk ikut menyesuaikan diri. Radio konvensional bisa jadi akan tertinggal jika tidak melakukan transformasi inovasi teknologi yang ada. Radio harus mampu menyesuaikan diri dengan kemajuan teknologi dan informasi. Kemajuan teknologi informasi akan berdampak pada dapat dinikmatinya siaran radio secara analog (AM//FM), digital, internet dan mobile (live streaming dan podcasting) serta situs jejaring (facebook, twitter, dII). Keberadaan teknologi konvensional yang berbasis analog dalam radio siaran telah dikembangkan menuju bentuk radio digital. Awalnya radio memanfaatkan frekuensi udara yang menghantarkan sinyal-sinyal analog ke masing-masing pesawat radio, namun kini teknologi komunikasi berkembang dan memunculkan radio internet. (Apriliani : 2011)

Berdasarkan hasil wawancara dengan pengelola radio siaran swasta di Kabupaten Kebumen bisa diperoleh informasi bahwa dalam menghadapi kemajuan teknologi dan informasi (internet, maraknya media online/digital, dsb.) yang begitu pesat saat ini, pengelola radio siaran melakukan berbagai upaya untuk menyesuaikan diri dengan perkembangan kemajuan teknologi dan informasi tersebut dengan menjalankan bisnis radio siaran menggunakan pola-pola bisnis modern. 
Hasil penelitian ini menunjukkan bahwa kebutuhan informasi masa kini terutama dalam bisnis radio siaran harus tetap menyesuaikan diri dengan kemajuan teknologi dan informasi. Radio siaran dituntut untuk menyesuaikan diri, seperti halnya dengan adanya facebook fanspage, twitter, instagram, whatsapp yang tentu saja merupakan kebutuhan masyarakat modern di masa sekarang ini. Salah satu radio siaran yang diteliti yaitu radio Bimasakti FM telah melakukan upaya penyesuaian diri diantaranya dengan adanya fanspage melalui facebook Radio Bimasakti dengan alamat url https://www.facebook.com/BimasaktiFM/, instagram radio Bimasakti https://www.instagram.com/bimasaktifm/ dengan 1,236 followers serta dalam melakukan komunikasi dengan pendengar selain menggunakan sms juga menggunakan whatsapp.

Seperti yang dilakukan oleh Radio Mas FM dengan dimilikinya alamat blog http://radiomasfmkebumen.blogspot.com/, instagram dengan akun https://www.instagram.com/masfmkebumen/, alamat facebook fanspage https://www.facebook.com/RadioMasFmKebumen/. Selain itu dalam menjalin komunikasi dengan audiens atau pendengar maka Mas FM selain menggunakan sms juga whatsapp dengan nomor 081836 1017.

Demikian halnya dengan Radio Bimasakti FM, stasiun radio ini juga melakukan penyesuaian diri dengan adanya kemajuan teknologi dan informasi dengan melakukan hal yang sama dengan Mas FM yaitu adanya alamat website http://www.cppradionet.com/bimasaktifm, Radio Bimasakti juga memiliki akun instagram https://www.instagram.com/bimasaktifm/, pemanfaatan media sosial facebook fanspage juga dilakukan oleh radio Bimasakti FM dengan alamat https://www.facebook.com/BimasaktiPopFM. Pada perusahaan radio siaran RPFM Gombong, penyesuaian diri dengan memanfaatkan kemajuan teknologi bahkan sudah sejak lama dengan terdaftarnya radio RPFM pada https://radio.garden/ dengan melakukan siaran streaming sejak tahun 2010 melalui https://radio.garden/listen/rpfm-104-mhz/2EANsBKV. Selain memiliki website www.purbowangifm.com radio ini juga memanfaatkan media sosial seperti facebook fanspage dengan alamat https://www.facebook.com/Purbowangifm/, serta twitter dengan akun https://twitter.com/104rpfm. Guna menyesuaikan dengan kemajuan teknologi dan informasi, radio Gong juga melakukan upaya yang sama dengan apa yang dilakukan oleh Mas FM, Bimasakti FM dan RPFM. Upaya tersebut dilakukan dengan terdapatnya website Radio Gong FM dengan alamat https://gongradio.id/, dimilikinya akun twitter https://twitter.com/gongradiofm. Radio Gong FM juga memanfaatkan media sosial facebook dengan alamat https://www.facebook.com/97.3.GongRadioGombong, serta terdapatnya akun instagram https://www.instagram.com/gongradiogombong/.

Meskipun kemajuan teknologi dan informasi sangat pesat, namun perlu disadari bahwa radio memiliki segmen tersendiri yang berbeda dengan media online seperti halnya internet. Untuk dapat mengakses internet maka perlu pulsa, perlu terhubung dengan jaringan yang itu semua tidak diperlukan ketika mendengarkan siaran radio. Namun radio tetap tidak menutup diri dengan perkembangan teknologi yaitu dengan cara menyesuaikan diri dengan kebutuhan pasar, diantaranya dengan melakukan siaran streaming (online) internet sehingga jangkauannya semakin global sampai ke mancanegara. Radio streaming saat ini memang sudah menjadi kebutuhan bagi pengelola perusahaan radio siaran hal ini sudah berkembang di Indonesia. Masyarakat Indonesia bisa mengakses radio streaming dari berbagai daerah bahkan yang berada di luar negeri. Hal ini sangat memudahkan kita yang berada di luar kota atau pun merantau ke luar negeri, apabila ingin mendengarkan siaran radio dari daerah asalnya. Sudah banyak radio swasta yang membuat radio streaming sehingga memudahkan kita untuk mengaksesnya. Radio streaming dapat didengarkan melalui internet, dapat juga melalui webcast seperti Winamp, iTunes dan win media player, maupun melalui software lainnya. Radio harus dapat mengikuti kemajuan teknologi seperti sekarang. Anak muda jaman sekarang lebih memilih youtube, internet dsb. Upaya yang dilakukan di lapangan adalah bagaimana agar anak muda dapat tetap 
mendengarkan radio meskipun teknologi informasi berkembang dengan pesat hal yang paling penting terutama bahwa radio mengantisipasi berita hoax. Radio memiliki keunggulan dapat menyiarkan beritaberita aktual. Kemajuan teknologi dan informasi terutama teknologi internet saat ini sudah menjadi kebutuhan penting bagi masyarakat. Upaya penyesuaian diri yang dilakukan bertujuan agar radio siaran tidak ditinggalkan oleh masyarakat atau pendengarnya karena masyarakat tetap dengan mudah dapat mengakses informasi maupun hiburan dengan cara atau sarana yang semakin maju/modern. Salah satu upaya penyesuaian diri dengan kemajuan teknologi adalah dengan melakukan siaran streaming. Namun pada empat radio yang diteliti baru terdapat dua stasiun radio siaran yang sudah melakukan hal tersebut yaitu radio RPFM Gombong melalui https://radio.garden/listen/rpfm-104-mhz/2EANsBKV dan Radio Gong FM Gombong melalui https://gongradio.id/ dan streaming melalui https://radio.garden/listen/gong-radio-gombong/a_9TLMTG sedangkan dua radio lainnya yaitu Bimasakti FM dan Mas FM belum melakukan namun sedang berproses ke arah tersebut. Guna meningkakan kualitas radio siaran, Mas FM memfokuskan pada peningkatan kualitas Sumber Daya Manusia melalui kegiatan forum kumpul bareng setiap satu bulan sekali bagi pihak manajemen dan penyiar.

Dengan adanya forum tersebut maka diharapkan akan terjadi diskusi yang mempertemukan berbagai ide, gagasan yang berguna bagi pengembangan dan peningkatan kualitas radio Mas FM. Lain halnya dengan yang dilakukan oleh Radio Bimasakti FM. Upaya untuk meningkatkan kualitas radio siaran dilakukan dengan mengadakan berbagai acara off air perempuan dengan mengundang narasumber untuk berbagi ilmu dengan audiens/pendengar/fans radio Bimasakti misalnya pembuatan kue tart, pembuatan marchendise, kerajinan dsb. Selain itu untuk lebih mendekatkan diri dengan masyarakat maka Radio Bimasakti FM juga mengisi acara di CFD (Car Free Day) setiap hari Minggu pagi di alun-alun kota Kebumen dengan melakukan body branding untuk mempromosikan stasiun radio tersebut. Peningkatan kualitas sumber daya manusia yang dilakukan RPFM melalui briefing internal yang dilakukan pada setiap hari Senin serta aktif mengikuti pelatihan karyawan/manajemen sepanjang pelatihan tersebut relevan dengan kebutuhan. Sebagai upaya mendekatkan diri dengan masyarakat maka acara off air juga pernah dilakukan dan bekerjasama dengan perusahaan seperti yang pernah dilakukan dengan Sanaflu dan Ultraflu dengan mengadakan panggung hiburan di Pasar Wonokriyo Gombong. Upaya meningkatkan kualitas sumber daya manusia pada Radio Gong FM dengan cara meningkatkan kemampuan sumber daya manusia yang bekerja di Radio Gong FM, pihak manajemen tidak hanya mengarahkan menjadi penyiar saja namun sebagai broadcaster dengan kemampuan yang semakin luas (menguasai programming, production, marketing, sampai ke kemampuan mengatasi permasalahan teknis).

Audiens memegang peranan yang sangat penting bagi radio siaran, maka diperlukan pemetaan terhadap audiens untuk mengetahui komposisi pendengar. Cara yang dilakukan untuk melakukan pemetaan audiens guna mendapatkan segmentasi pasar yang tepat melalui fanspage di facebook, whatsapp, sms dan telepon. Dengan demikian akan dapat diketahui dari mana pendengar berasal dan pada rentang usia berapa. Penting bagi radio siaran untuk melakukan pemetaan audiensnya. Bimasakti FM melakukan pemetaan melalui berbagai media diantaranya facebook fanspage, whatsapp, sms dan telepon sehingga dapat diketahui dari mana pendengar berasal dan pendengar dapat dikelompokkan pada berbagai rentang usia. Sedangkan RPFM melakukan pemetaan audiens dengan melihat sms yang masuk, melihat pada saat acara-acara pengajian yang diselenggarakan RPFM sehingga dapat bertemu langsung dengan audiens/pendengar. Serta segmentasi pendengar juga dapat dilihat dari respons pada masing-masing acara. Radio Gong FM melakukan pemetaan audiens dengan terlebih dahulu melakukan studi kelayakan (feasibility study) untuk menentukan segmentasi pendengar. Dari hasil pemetaan tersebut di ketahui strata ekonominya, tingkat pendidikan, perilaku masyarakat sehingga akan memudahkan radio siaran untuk menyusun/membuat program acara yang sesuai dengan apa yang diinginkan/dibutuhkan oleh pendengar. Rentang usia juga berpengaruh terhadap acara yang akan diprogramkan 
Radio lebih unggul dalam hal jangkauan. Radio siaran mampu menjangkau masyarakat luas dalam hal penyampaian informasi dan tidak terbatas oleh kondisi geografis sehingga radio merupakan media yang efektif dalam penyampaian informasi.

\section{SIMPULAN}

Berdasarkan hasil penelitian yang telah dilakukan di Kabupaten Kebumen pada empat perusahaan radio siaran dapat diketahui bahwa pada keempat perusahaan radio siaran tersebut telah melakukan upaya penyesuaian diri dalam menghadapi kemajuan teknologi dan informasi (internet, maraknya media online/digital, dsb.) yang begitu pesat saat ini. Upaya yang dilakukan bertujuan untuk mempertahankan eksistensi radio siaran dalam persaingan global yang semakin terbuka dan semakin modern.

Perusahaan radio siaran melakukan penyesuaian diri dengan kemajuan teknologi dan informasi dengan tidak hanya stagnan pada konsep radio konvensional namun menambahkan aplikasi media berbasis internet seperti website, blog, instagram, facebook fanspage, dan sebagainya.

Pada keempat radio siaran yang diteliti upaya yang dilakukan dalam menghadapi kemajuan teknologi dan informasi telah dilakukan dengan berbagai cara melalui pemanfaatan teknologi berbasis internet. Upaya yang dilakukan untuk meningkatkan kualitas sumber daya manusia pada radio siaran sebagai media komunikasi, sekaligus sebagai sarana hiburan dan informasi yang berorientasi bisnis, maka pada keempat radio siaran yang diteliti melakukan beberapa upaya yang berbeda disesuaikan dengan karakteristik radio siaran masing-masing.

Untuk mendapatkan segmentasi pasar atau audiens yang tepat, maka keempat perusahaan radio siaran yang diteliti melakukan berbagai upaya yang berbeda-beda disesuaikan dengan kondisi masing-masing radio siaran.

Upaya menyesuaikan diri dengan kemajuan teknologi dan informasi mutlak harus dilakukan oleh perusahan radio siaran agar tidak ditinggalkan oleh pendengarnya. Kebutuhan masyarakat modern yang semakin maju dan dinamis harus menjadi pertimbangan utama perusahaan radio siaran untuk menambahkan berbagai sarana teknologi dan informasi yang dapat mempermudah masyarakat untuk mengakses siaran radio yang diselenggarakan. Upaya yang harus dilakukan diantaranya adalah melakukan perluasan jangkauan siaran radio secara global dengan menambahkan siaran streaming berbasis internet disamping melakukan siaran konvensional melalui frekuensi radio FM.

Dalam menjalin komunikasi dengan audiens, stasiun radio siaran hendaknya menambahkan model komunikasi modern masa kini melalui whatsapp, twitter, serta jejaring/media sosial yang lainnya sehingga segmentasi pendengar menjadi semakin bertambah luas.

Perusahaan radio siaran harus senantiasa melakukan peningkatan kualitas sumber daya manusia baik melalui forum-forum internal (rapat, breafing, diskusi) maupun dengan mengikuti berbagai program peningkatan kualitas sumber daya secara eksternal melalui pelatihan, workshop, seminar, dan sebagainya karena dengan kualitas sumber daya manusia yang semakin baik akan meningkatkan kualitas pengelolaan radio siaran sehingga perusahaan radio siaran akan tetap dapat mempertahankan eksistensinya.

\section{REFERENSI}

Aprilani, 2011. Radio Internet Dalam Perspektif Determinisme Teknologi. Jurnal Komunikasi, Vol.1 (2).

Cangara, H. H. 2006. Pengantar Ilmu Komunikasi, PT. Raja Grafindo Persada. Jakarta.

Effendy, O. U. 2002. Ilmu Komunikasi Teori dan Praktek, Remadja Karya, Bandung 
Effendi, O. U. 1993. Televisi Siaran Teori dan Praktek. Bandung Mandar Maju.

Effendi, O. U. 1997. Kepemimpinan dan Komunikasi, Alumni, Bandung

http://www.cppradionet.com/bimasaktifm/profile.html, diunduh tanggal 10 April 2019

https://kebumenkab.go.id/index.php/public/diseminasi/detail/45, diunduh tanggal 10 April 2019

https://kominfo.kebumenkab.go.id/web/post/lembaga-penyiaran7, diunduh tanggal 10 April 2019

Moloeng, L. J. 2007. Metodologi Penelitian Kualitatif. Penerbit PT. Remaja Rosda Karya Bandung,

Panuju, R. 1995. Komunikasi Bisnis, Penerbit PT. Gramedia Pustaka Utama, Jakarta

Respati, Wira. 2014. Transformasi Media Massa Menuju Era Masyarakat Informasi Di Indonesia. Jurnal Humaniora, Vol 5(1), 39-51.

Sari, S.D.S.R. dan Ismail, E. 2016. Survey Perilaku Mendengarkan Radio di Jakarta. Jurnal Visi Komunikasi, Vol 15(1), 1-15.

Undang-Undang Nomor 32 Tahun 2002 